\title{
ANALISIS HUKUM ISLAM TERHADAP PRAKTIK GADAI SAWAH
}

\author{
Oleh \\ Subekan \\ Institut Agama Islam Pangeran Diponegoro Nganjuk
}

\begin{abstract}
Islam is a religion that is universal and applies throughout the ages. The eternity and power of Islam has been proven throughout its history, where every period of time and the development of human civilization has always been completely answered by the teachings of Islam through the Qur'an as its foundation. Including the issue of paddy pledges, this is sticking out because one party feels lucky or even feels disadvantaged. So in the context of Islamic law this is certainly far from the principle of Islamic Economics. Like the practice of paddy pawning in Salamrojo Village, Berbek District, Nganjuk Regency. In general, pawning practices carried out by local communities have met the requirements and pillars of pawning. However, there are several things that need to be addressed such as the management of collateral goods and the distribution of collateral goods. Because with this lack of clarity, in the end there is a prejudice that one party feels benefited or disadvantaged. In addition there is a difference of opinion among Imam Mazhab regarding the use of pawn collateral items by the pawning recipient. But clearly it can be said that there are differences of opinion among Islamic scholars in discussing the use of goods pawning is a reference for parties in pawning transactions (rahn) to be able to choose or find a middle ground in terms of the use of pawning goods in accordance with the needs and conditions that exist, so that the purpose the main mortgage is not overlooked.
\end{abstract}

Keywords: Islamic Law, Gadai Sawah

\begin{abstract}
Abstrak
Islam merupakan agama yang bersifat universal dan berlaku sepanjang zaman. Keabadian dan kekuatan Islam telah terbukti sepanjang sejarahnya, dimana setiap kurun waktu dan perkembangan peradaban manusia senantiasa dijawab dengan tuntas oleh ajaran Islam melalui AlQur'an sebagai landasannya. Termasuk persoalan gadai sawah, hal ini
\end{abstract}


mencuat lantaran salah satu pihak ada yang merasa untung atau bahkan merasa dirugikan. Maka dalam konteks hukum Islam tentu ini jauh dari prinsip Ekonomi Syariah. Seperti praktik gadai sawah yang ada di Desa Salamrojo Kecamatan Berbek Kabupaten Nganjuk. Secara umum praktik gadai yang dilakukan masyarakat setempat sudah memenuhi syarat dan rukun gadai. Namun, ada beberapa hal yang perlu dibenahi seperti pengelolaan barang jaminan dan pembagian hasil barang jaminan. Karena dengan ketidak jelasan hal tersebut, pada akhirnya timbul prasangka bahwa salah satu pihak merasa diuntungkan atau dirugikan.Selain itu ada perbedaan pendapat dikalangan Imam Mazhab mengenai pemanfaatan barang jaminan gadai oleh penerima gadai. Namun secara jelas dapat dikatakan bahwa adanya perbedaan pendapat dikalangan ulama Madzhab dalam membahas pemanfaatan barang gadai merupakan referensi bagi para pihak dalam transaksi gadai ( $r a h n)$ untuk dapat memilih atau mencari jalan tengah dalam hal pemanfaatan barang gadai sesuai dengan kebutuhan dan kondisi yang ada, sehingga tujuan utama gadai tidak terabaikan.

Kata Kunci: Hukum Islam, Gadai Sawah

\section{Pendahuluan}

Islam merupakan agama yang bersifat universal dan berlaku sepanjang zaman. Keabadian dan kekuatan Islam telah terbukti sepanjang sejarahnya, dimana setiap kurun waktu dan perkembangan peradaban manusia senantiasa dijawab dengan tuntas oleh ajaran Islam melalui Al-Qur'an sebagai landasannya. Keuniversalan konsep Islam merupakan jawaban terhadap keterbatasan manusia dalam berpikir.

Dalam menjawab permasalahan yang timbul nampaknya peran hukum Islam dalam konteks kekinian dan kemodernan dewasa ini sangat diperlukan dan tidak dapat dihindarkan lagi. Kompleksitas permasalahan umat yang selalu berkembang seiring dengan perkembangan zaman membuat hukum Islam harus menampakkan sifat elastisitas dan fleksibilitasnya guna memberikan yang terbaik serta memberikan kemaslahatan bagiumatnya. ${ }^{71}$

71 Muhammad Sholikul Hadi, Pegadaian Syari'ah, Jakarta: Salemba Diniyah,cet 2011, h.2 
Agama Islam juga mengajarkan kepada umatnya supaya hidup tolong- menolong. Bentuk dari tolong-menolong ini bisa berupa pemberian, pinjaman, atau utang-piutang. Dalam suatu perjanjian utangpiutang, debitur sebagai pihak yang berutang meminjam uang atau barang dari kreditur sebagai pihak yang berpiutang. Agar kreditur memperoleh rasa aman dan terjamin terhadap uang yang dipinjamkan, kreditur mensyaratkan sebuah agunan atau jaminan. Agunan ini di antaranya bisa berupa gadai atas barang- barang yang dimiliki oleh debitur. Debitur sebagai pemberi gadai menyerahkan barang-barang yang digadaikan tersebut kepada kreditur atau penerima gadai. ${ }^{72}$

Gadai merupakan salah satu katagori dari perjanjian utangpiutang. Praktik semacam ini telah ada pada zaman Rasulullah SAW. Dan Rasulullah sendiri pernah melakukan. Gadai mempunyai nilai sosial yang sangat tinggi dan dilakukan secara suka rela atas dasartolong-menolong. ${ }^{73}$

Dalam pelaksanaannya, si pemegang gadai berhak menguasai benda yang digadaikan kepadanya selama hutang si berhutang belum lunas, tetapi ia tidak berhak mempergunakan benda itu. Selanjutnya ia berhak menjual gadai itu, jika si berhutang tidak bisa membayar hutangnya. Jika hasil penjualan gadai itu lebih besar dari pada hutang yang harus dibayar, maka kelebihan itu harus dikembalikan kepada si penggadai. ${ }^{74}$ Tetapi jika hasilitu tidak mencukupi pembayaran hutang, maka si pemiutang tetap berhak menagih piutang yang belum dilunasi itu. Penjualan gadai harus dilakukan di depan umum sebelum penjualan dilakukan biasanya hal itu harus diberitahukan lebih dahulu kepada si penggadai. Tentang pelunasan hutang, pemegang gadai selalu didahulukan daripada pemiutanglainya. ${ }^{75}$

${ }^{72}$ www. makalah gadai syari'ah. Id. Com.18/J1 nuari/2010

73 Muhammad Sholikul Hadi, Pegadaian Syari'ah, Jakarta: Salemba Diniyah,cet 2011

M. Ali Hasan, Berbagai Macam Transaksi dalam Islam (Fikih Muamalat), Jakarta: PT. Raja Grafido Persada,cet 2011, H..253.

${ }^{75}$ M. Ali Hasan, Berbagai Macam Transaksi dalam Islam (Fikih Muamalat), Jakarta: PT. Raja Grafido Persada,cet 2011, 254 
Di Desa Salamrojo Kecamatan Berbek Kabupaten Nganjuk, ada cara gadai yang hasil barang gadaian itu, langsung dimanfaatkan oleh penerima gadai (orang yang memberi piutang). Banyak terjadi di Desa itu, bahwa sawah yang dijadikan barang jaminan gadai langsung dikelola oleh penerima gadai dan hasilnya pun sepenuhnya dimanfaatkan oleh penerima gadai. Pada dasarnya pemilik barang, dapat mengambil manfaat dari barang yang digadaikan. Kendati pemilik barang (jaminan) boleh memanfaatkan hasilnya, tetapi dalam beberapa hal dia tidak boleh bertindak untuk menjual, mewakafkan, atau menyewakan barang jaminan itu, sebelum ada persetujuan dari penerima gadai.

Olehkarena itu apakah sudah benar, pelaksanaann gadai yang dilakukan oleh masyarakat di Desa Salamrojo Kecamatan Berbek Kabupaten Nganjuk menurut Hukum Islam? Mereka memiliki keterbatasan infomasi tentang gadai atau rahn, yang seharusnya mereka pahami sebelum mereka melakukan transaksi gadai itu. Sebagian masyarakat di Desa tersebut melakukan gadai secara perorangan. Kebanyakan mereka melakukan gadai itu dengan jaminan sawah yang masih produktif. Karena kebanyakan penerima gadai tidak menginginkan jika sawah yang dijadikan jaminan gadai tidak produktif.

\section{Metode Penelitian}

Dilihat dari segi metodologis, penelitian ini merupakan jenis penelitian kualitatif. Adapun penelitian kualitatif adalah suatu prosedur penelitian yang menghasilkan data deskriptif berupa katakata tertulis maupun lisan dari orang-orang dan perilaku yang dapat diamati. Penanganan ini diarahkan pada latar dari individu tersebut secara holistik. Jenis penelitian ini adalah penelitian deskriptif (descriptive research) yaitu untuk eksploitasi dan klarifikasi mengenai suatu fenomena atau kenyataan sosial, dengan jalan mendeskripsikan sejumlah variabel yang berkenaan dengan masalah dan unit yang diteliti.

Sesuai dengan jenis penelitian maka kehadiran peneliti mutlak diperlukan, karena peneliti sebagai instrumen utama peneliti membuat rancangan, pengamatan, wawancara, pengumpulan data, dan menganalisis data serta sebagai pelapor hasil penelitian. Sebagai 
langkah awal penelitian, peneliti mendatangi Desa Salamrojo setelah mendapatkan ijin, maka peneliti akan terjun langsung ke lapangan untuk melakukan wawancara dan menggali informasi.

Sumber data dalam penelitian ini adalah kumpulan pengamatan penulis terhadap fenomena-fenomena, data-data, serta jurnal-jurnal ilmiah yang terkait dengan judul yang diteliti. Adapun data primer dalam penelitian ini dilakukan dengan melalui wawancara dengan Kepala Desa Salamrojo serta msyarakat yang berkaitan dengan penelitian, dan observasi langsung terhadap proses Gadai di Desa Salamrojo Kecamatan Berbek Kabupaten Nganjuk. Sedangkan data sekunder dalam penelitian ini adalah studi terhadap karya tulis ilmiah, jurnal, dan dokumen yang berkaitan dengan topik yang sedang diteliti, ataupun obyek penelitian.

Analisis data dalam proses iniyaitu mengorganisasikan dan mengurutkan data ke dalam pola, kategori, dan satuan uraian dasar sehingga dapat ditemukan tema dan dapat dirumuskan hipotesis kerja seperti yang disarankan oleh data. Tujuan analisa data adalah menyempitkan dan membatasi penemuan-penemuan sehingga menjadi suatu data yang teratur, tersusun dan lebih berarti. Proses analisis data yaitu mencatat yang menghasilkan catatan lapangan, dengan hal itu diberi kode agar sumber datanya tetap dapat ditelusuri. Kemudian mengumpulkan, memilah-milah, mengklasifikasikan, mensintesiskan, membuat ikhtisar, dan membuat indeksnya. Serta berpikir, dengan jalan membuat agar kategori data itu mempunyai makna, mencari dan menemukan pola dan hubungan-hubungan, dan membuat temuantemuan umum.

\section{Hasil Dan Pembahasan}

\section{Segi Akad dan Akibat Hukumnya}

Dari hasil penelitian yang telah dilakukan peneliti mendapatkan poin-poin penting yang menjadi bahan untuk dianalisis, serta dapat diketahui juga bahwa praktik pelaksanaan gadai sawah di desa Salamrojo Kecamatan Berbek Kabupaten Nganjuk masih perlu banyak evaluasi secara cermat. 
Apabila dilihat dari pihak yang melaksanakan akad, maka praktik gadai sawah yang terjadi di Desa Salamrojo telah dipandang sah dan benar menurut pandangan hukum Islam. Walaupun ijab qabulnya tidak menggunakan kata-kata atau surat perjanjian tertentu yang mengikat antara kedua belah pihak, akan tetapi kedua belah pihak telah faham bahwa mereka telah melakukan akad perjanjian. Rahin selaku pihak yang menggadaikan sawahnya kepada murtahin telah memenuhi syarat yang telah diatur dalam aturan Islam, dimana rahin merupakan orang yang sudah cakap dalam melakukan tindakan hukum, telah aqil baligh, tidak gila dan mampu untuk melakukan akad tanpa harus mewakilkan kepada orang lain. Akad dikatakan tidak sah apabila rahin merupakan orang gila ataupun orang yang belum tamyiz.

Dilihat dari murtahin selaku pihak yang melaksanakan perjanjian dalam pelaksanaan gadai sawah di Desa Salamrojo telah sesuai atau sah menurut pandangan hukum Islam, karena murtahin selaku subyek yang akan mengadakan transaksi gadai sawah dan menjadi penerima sawah yang akan digadaikan oleh rahin telah memenuhi syarat yang telah tercantu dalam aturan Islam, dimana murtahin merupakan orang yang cakap dalam melaksanakan tindakan hukum, kemudian juga kedua belah pihak melakukannya tanpa ada paksaan, suka rela atau intimidasi dari pihak manapun.

Dilihat dari rukun gadai yang berupa hutang menurut peneliti, hutang yang menjadi penyebab adanya transaksi gadai tersebut juga telah sah dan benar sesuai hukum Islam. Hal ini dikarenakan hutang tersebut dapat dihitung jumlahnya. Bukan hutang yang bersifat tidak pasti ataupun hutang yang tidak dapat diketahui jumlahnya.

Pelaksanaan gadai yang terbagi menjadi tiga macam bentuk gadai sawah yang berlangsung di Desa Salamrojo bagi para pihaknya merupakan suatu sarana saling membantu antara tetangga maupun saudaranya yang sedang kesulitan biaya. Hal ini membuat kedua belah pihak merasa rela membantu, dimana tidak 
ada unsur paksaan dari kedua pihak. Murtahin selaku penerima gadai tidak ada tujuan tekanan terhadap rahin untuk segera melunasi hutangnya.

Dari sisi bentuk gadai yang ada di Desa Salamrojo secara syarat dan rukun gadai telah terpenuhi dan sah menurut hukum Islam tetapi dari pelaksanaannya muncul masalah terkait hasil pemanfaatan sawah yang harusnya milik rahin beralih ke murtahin setelah terjadinya akad. Dalam hukum Islam seharusnya yang memiliki hak atas pengelolaan serta mengambil manfaat dari sawah itu adalah rahin.

Apabila sawah yang menjadi barang jaminan gadai tidak boleh dimanfaatkan oleh kedua belah pihak karena rahin hanya memiliki barang tersebut sementara murtahin tidak memiliki hak untuk mengambil manfaat barang tersebut atau mendapatkan hasilnya, maka yang terjadi akan menyebabkan kerusakan dan tidak mendatangkan manfaat. Oleh sebab itu pola berfikir masyarakat supaya menghindari kemubaziran, sesuai kesepakan diawal akad masyarakat Desa Salamrojo biasanya murtahin mendapat izin dari rahin untuk memanfaatkan sawah sebagai barang jaminan maka diperbolehkan dengan ketentuan ada bagi hasil pertanian antara kedua pihak (muzara'ah).

Pemanfaatan sawah sebagai barang jaminan ada yang digarap oleh rahin, murtahin, maupun buruh tani sesuai bentuk gadai sawah yang terbagi menjadi tiga macam serta dalam pelaksanaan pemanfaatan sawah sama-sama terdapat akad muzara'ah yang menyatu pada akad gadai. Hal ini sudah menjadi hal yang wajar di masyarakat Desa Salamrojo, bahwa setelah akad dilaksanakan yang berhak memanfaatkan sawah adalah pihak-pihak yang telah disebutkan diatas sesuai bentuk gadai yang ada selama minimal dua tahun. Apabila dalam waktu tersebut rahin belum mengembalikan hutangnya, maka sawah tersebut masih dalam penguasaan murtahin sampai rahin melunasi hutangnya. 


\section{Penyebab terjadinya Praktik Gadai Sawah}

Ternyata ptaktik gadai yang terjadi di Desa ini bukan tanpa sebab, ada beberapa hal yang melatarbelakangi pemilik sawah menggadaikan asetnya miliknya. Secara umum disebabkan oleh kebutuhan yang harus segera dipenuhi. Berikut ini beberapa penyebab praktik gadai sawah yaitu:

1. Gadai Sawah untuk Biaya pendidikan

Kondisi sarana pendidikan yang ada di desa Salamrojo yang hanya tersedia sampai jenjang SMP mengharuskan masyarakat yang ingin melanjutkan anaknya dalam sekolah maupun kuliah harus mengeluarkan biaya tambahan. Hal itu sebagai upaya untuk memberikan kesempatan pada anak mereka untuk mengenyam pendidikan yang lebih tinggi. Hal inilah yang menjadikan alasan kenapa harus menggadaikan sawah yang dimilikinya.

Biaya pendidikan menjadi salah satu alasan kenapa harus menggadaikan sawah yang dimiliki seseorang. Biaya pendidikan yang dimaksud adalah biaya transportasi, biaya buku maupun biaya yang lain. Apalagi sampai disekolahkan ke lintas desa bahkan kecamatan atau kota. Kemampuan ekonomi yang kurang memadai karena faktor pekerjaan yang hanya tergantung pada pendapatan petani atau kuli bangunan mengharuskan seseorang yang hidup di desa tersebut harus memutar otak supaya mampu menjadikan anaknya dapat mengenyam pendidikan yang lebih tinggi, walaupun pendapatan mereka lebih dari cukup untuk biaya sehari-hari untuk kebutuhan makanan bukan berarti mereka akan tercukupi ketika dihadapkan pada kondisi dimana mengharuskan membutuhkan biaya yang lebih banyak. Salah satunya adalah biaya untuk pendidikan SMA dan perguruan tinggi. Hal ini disebabkan karena mengharuskan mereka melanjutkan pendidikan tersebut di daerah lain.

2. Gadai Sawah untuk Usaha

Minimnya modal dan kurang pengetahuan sebagian masyarakat Salamrojo terkait pengelolaan sawah yang dimilikinya mengantarkan mereka kepada pemikiran yang 
berbeda yaitu mereka ingin mencoba untuk memulai usaha dibidang lainnya. Sawah yang dimiliki oleh mereka dijadikan modal sebagai sarana untuk mendapatkan uang supaya nantinya mampu membuka atau dibuat modal usaha lainnya.

Banyak masyarakat yang tertarik untuk menjalankan suatu usaha sementara disatu sisi dia membutuhkan modal tambahan supaya mampu membeli mesin dan lahan untuk dijadikan galian. Maka, dia mencoba untuk beralih profesi dari seorang petani menjadi seorang pekerja batu. Sehingga dia pertimbangan tersebut dia menggadaikan sawah yang dimilikinya untuk kepentingan usaha tersebut.

\section{Perspektif Hukum Islam Terhadap Pelaksanaan Gadai Sawah}

Secara keseluruhan dalam pelaksanaan gadai sawah di Desa Salamrojo, dari ketiga bentuk gadai yang ada sama-sama menyatukan akad muzara'ah dalam akad gadai. Perbedaanya terdapat pada proses penggarapan sawah yang pada gadai ncromo dilimpahkan kepada pihak rahin itu sendiri, ada yang digarap langsung oleh murtahin, yang terakhir menyuruh buruh untuk menggarap sawah gadai.

Maka setelah peneliti mengetahui fakta yang terjadi diatas, dapat dipahami bahwa pelaksanaan gadai sawah yang terbagi menjadi tiga macam di Desa Salamrojo menggunakan sistem satu akad dalam dua transaksi dikarenakan didalam akad gadai terdapat akad muzara'ah atau bagi hasil pertanian sehingga akad muzara'ah itu tidak berdiri sendiri melainkan menjadi satu dalam akad gadai yang dilakukan diawal perjanjian. Jadi akad muzara'ah itu terikat atau menyatu dalam akad gadai. Praktek dua transaksi dalam satu akad terlarang oleh hukum Islam berdasarkan hadits Nabi berikut ini. 


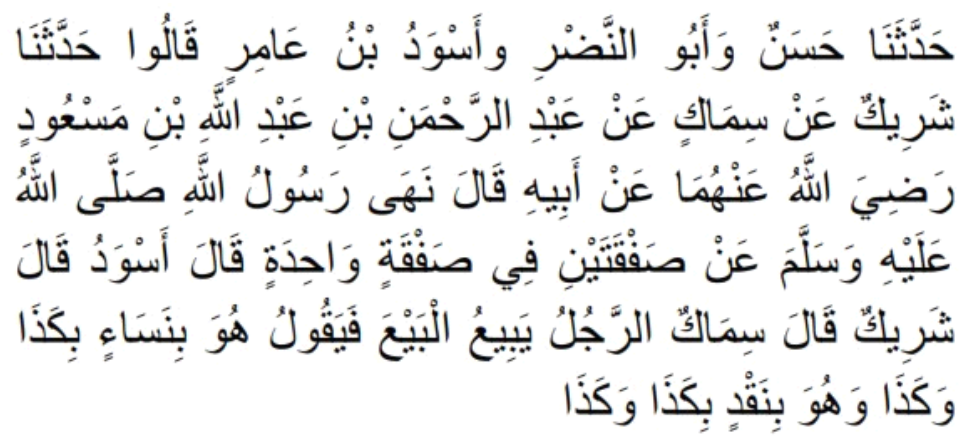

Artinya : Telah menceritakan kepada kami Hasan dan Abu Nadlr dan Aswad bin Amir mereka berkata; Telah menceritakan kepada kami Syarik dari Simak dari Abdurrahman bin Abdullah bin Mas'ud radliallahu 'anhuma dari ayahnya berkata; Rasulullah shallallahu 'alaihi wasallam melarang dua transaksi dalam satu akad. Aswad berkata; Syarik berkata; Simak berkata; Seorang laki-laki menjual barang jualan seraya mengatakan; Ia dengan kredit sekian dan sekian dan dengan tunai sekian dan sekian. (AHMAD- 3595)

Hadits lain yang tidak memperbolehkan dalam satu akad terdapat dua transaksi:

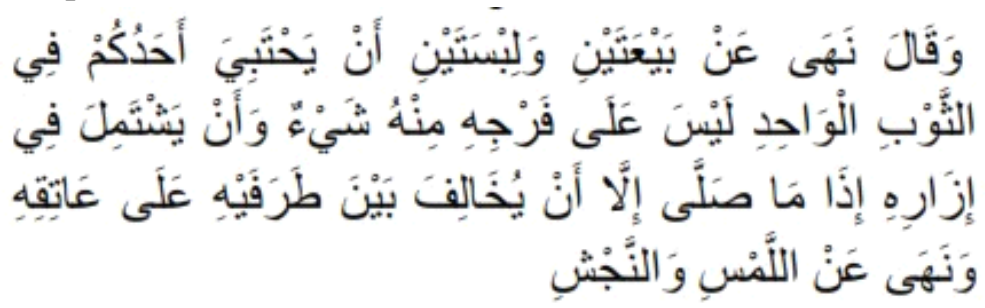

Artinya : Masih melalui jalur periwayatan yang sama seperti hadits sebelumnya; dari Abu Hurairah; berkata: Rasulullah melarang dua transaksi dalam satu akad jual beli dan dua cara berpakaian; yaitu salah seorang berihtiba' (duduk di atas bokong dengan mengumpulkan kedua pahanya menempel dada) dengan satu kain sedang pada daerah kemaluannya tidak ada sesuatu yang menutupinya, dan menyelimuti badannya dengan satu kain sarungnya ketika shalat kecuali jika kedua ujungnya 
diserempangkan pada pundaknya. Dan Rasulullah juga melarang dari jual beli dengan sistem Al Lams (barang siapa memengang maka wajib beli) dan An Najsy (menambah harga barang dengan tujuan untuk menipu pembeli)." (AHMAD 7903)

Dari tiga macam bentuk gadai sawah dalam pemanfaatan barang gadai di Desa Salamrojo kurang sesuai dengan prinsip muamalah. Karena sudah peneliti jelaskan pada pembahasan sebelumnya bahwa gadai bukan termasuk dalam akad pemindahan hak milik, gadai bukan merupakan kepemilikan keseluruhan atas suatu benda untuk pemanfaatan suatu barang, melainkan hanya sekedar untuk jaminan dalam akad hutang piutang. Dengan hal itu para ulama sepakat bahwa hak milik serta hak untuk memanfaatkan barang jaminan masih berada pada pihak rahin. Murtahin sebagai penerima gadai tidak boleh mengambil manfaat barang gadaian kecuali mendapat izin dari rahin. Hal ini berdasarkan hadits Nabi SAW sebagai berikut:

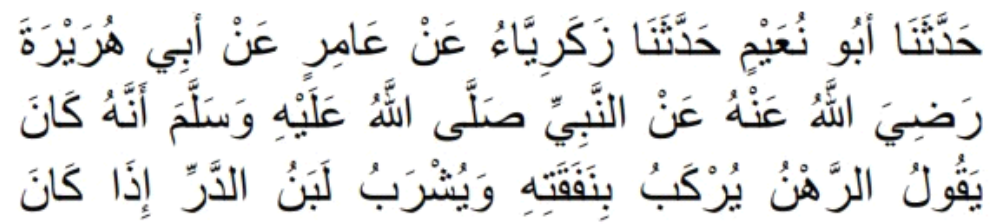

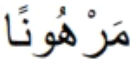

Artinya : Telah menceritakan kepada kami Abu Nu'aim menceritakan kepada kami Zakariya' 'Amir dari Abu Hurairah R.A dari Nabi SAW bersabda: "Sesuatu (hewan) yang digadaikan boleh dikendarai untuk dimanfaatkan, begitu juga susu hewan boleh diminum bila digadaikan". (Imam Bukhori)

Dilihat dari obyeknya, barang gadai dapat dibedakan menjadi dua macam. Benda yang bersifat tetap dan benda yang bergerak. Jadi pembiayaan barang gadai juga terbagi menjadi dua bagian, yaitu barang yang membutuhkan biaya perawatan dan tidak membutuhkan biaya perawatan. Untuk biaya yang 
membutuhkan biaya perawatan murtahin diperbolehkan mengambil pemanfaatan barang sesuai dengan hasil biaya yang dikeluarkan untuk ongkos perawatanya, hal ini berdasarkan hadits :

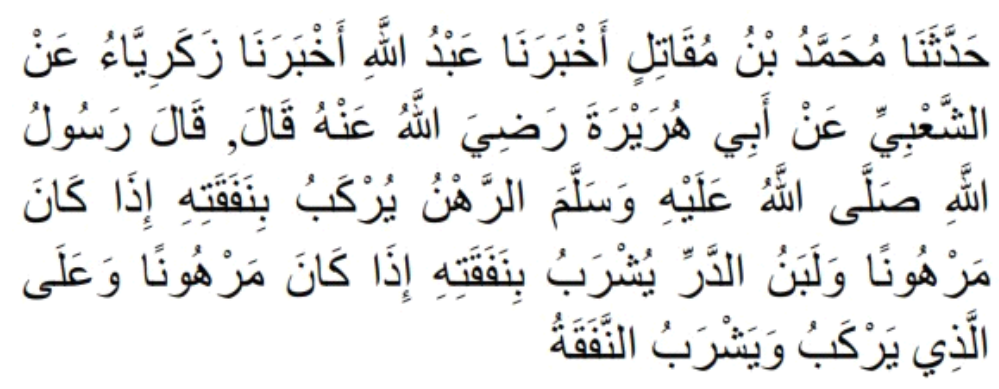

Artinya : Telah menceritakan kepada kami Muhammad bin Muqatil telah mengabarkan kepada kami 'Abdullah telah mengabarkan kepada kami Zakariya' dari Asy-Sya'biy dari Abu Hurairah radliallahu 'anhu berkata; Rasulullah shallallahu'alaihi wasallam bersabda: "(Hewan) boleh dikendarai jika digadaikan dengan pembayaran tertentu, susu hewan juga boleh diminum bila digadaikan dengan pembayaran tertentu, dan terhadap orang yang mengendarai dan meminum susunya wajib membayar". ( Imam Bukhari - 2329)

Hadits diatas dapat difahami bahwa murtahin baru dapat memanfaatkan barang gadai, jika barang tersebut membutuhkan biaya perawatan atau pemeliharaan. Dapat dipahami bahwa yang dimaksud hadits diatas jika barang jaminan hutang tersebut berupa hewan ternak yang memerlukan biaya perawatan. Sawah sebagai obyek gadai merupakan barang jaminan yang dipandang sah menurut aturan Islam, karena sawah merupakan barang yang jelas milik sendiri bukan milik orang lain. 


\section{Kesimpulan}

Dilihat dari syarat dan rukun gadai, maka akad dalam transaksi gadai sawah Desa Salamrojo sudah sah dan dibenarkan menurut hukum Islam, karena telah memenuhi unsur sahnya gadai yaitu adanya aqid selaku rahin dan murtahin, sighat akad atau ijab kabul antara rahin dan murtahin, marhun selaku barang jaminan, dan marhun bih atau hutang. Syarat dan rukun gadai yang terjadi pada masyarakat Desa Salamrojo dapat dibenarkan karena para pihak memiliki kecakapan dalam melakukan tindakan hukum secara suka rela.

Selanjutnya, praktek gadai sawah yang seharusnya menjadi barang jaminan justru dimanfaatkan dan diperoleh hasilnya, serta dalam pelaksanaannya dikaitkan dengan sistem akad muzara'ah, ini mengakibatkan terdapat sistem akad muzara'ah yang menyatu didalam akad gadai yang dailakukan pada awal transaksi gadai sawah.

Masyarakat setempat menggadaikan sawah karena beberapa penyebab yaitu 1) Untuk Biaya pendidikan. Kondisi sarana pendidikan yang ada di desa Salamrojo yang hanya tersedia sampai jenjang SMP mengharuskan masyarakat yang ingin melanjutkan anaknya dalam sekolah maupun kuliah harus mengeluarkan biaya tambahan. Hal itu sebagai upaya untuk memberikan kesempatan pada anak mereka untuk mengenyam pendidikan yang lebih tinggi. Hal inilah yang menjadikan alasan kenapa harus menggadaikan sawah yang dimilikinya. 2) Gadai Sawah untuk Usaha. Minimnya modal dan kurang pengetahuan sebagian masyarakat Salamrojo terkait pengelolaan sawah yang dimilikinya mengantarkan mereka kepada pemikiran yang berbeda yaitu mereka ingin mencoba untuk memulai usaha dibidang lainnya. Sawah yang dimiliki oleh mereka dijadikan modal sebagai sarana untuk mendapatkan uang supaya nantinya mampu membuka atau dibuat modal usaha lainnya.

Secara keseluruhan dalam pelaksanaan gadai sawah di Desa Salamrojo, dari ketiga bentuk gadai yang ada sama-sama menyatukan akad muzara'ah dalam akad gadai. Perbedaanya terdapat pada proses 
penggarapan sawah yang pada gadai ncromo dilimpahkan kepada pihak rahin itu sendiri, ada yang digarap langsung oleh murtahin, yang terakhir menyuruh buruh untuk menggarap sawah gadai. Maka setelah peneliti mengetahui fakta yang terjadi diatas, dapat dipahami bahwa pelaksanaan gadai sawah yang terbagi menjadi tiga macam di Desa Salamrojo menggunakan sistem satu akad dalam dua transaksi dikarenakan didalam akad gadai terdapat akad muzara'ah atau bagi hasil pertanian sehingga akad muzara'ah itu tidak berdiri sendiri melainkan menjadi satu dalam akad gadai yang dilakukan diawal perjanjian. Jadi akad muzara'ah itu terikat atau menyatu dalam akad gadai.

\section{Saran}

Dengan adanya beberapa uraian di atas, maka penulis memberikan saran-saran untuk menjadi bahan pertimbangan. Kepada pihak rahin dan murtahin, ketika melakukan transaksi gadai sawah hendaknya menyertakan barang tersebut dengan sertifikat tanah sebagai bukti nyata bahwa kepemilikan atas sawah tersebut jelas, agar dapat menjadi jaminan barang yang sesuai. Dalam melakukan gadai, antara penggadai dan penerima gadai harus ada kejelasan waktu pengembalian hutang, sehingga pelaksanaan gadai tidak berlarut lama. Kepada pihak rahin, ketika telah memiliki uang segeralah menebus barang jaminan gadai itu jangan samapai menunda pembayaran. Supaya tidak menimbulkan anggapan bahwa murtahin mendapat keuntungan yang berlipat dari hasil gadai tersebut. Kepada Murtahin Dalam pemenfaatan barang jaminan, keuntungan dari pengelolaan barang jaminan harus dibagi dengan system bagi hasil.

Hendaknya senantiasa mendampingi dan menjembatani masyarakat dalam bermuamalah. Sehingga tidak terjadi hal-hal yang merugikan kedua belah pihak. Dalam pelaksanaan praktik gadai prinsip ta'awwun jangan sampai terabaikan. Kepada Masyarakat, ketika akan melakukan proses gadai seyogyanya mencari penjelasan sejelas - jelasnya tentang tata cara yang sesuai dengan syari’at Islam. 


\section{Daftar Pustaka}

Ali As'ad, terjemah fathul mu'in, terj. H. Moh. Tolchah Mansoer, Kudus: Menara Kudus, hlm.215.

Al-Faqih Abul Wahid Muhammad Bin Achmad Bin Muhammad Ibnu

Rusyd, Bidayatul Mujtahid Wa Nihayatul

Muqtashid, Jakarta: Pustaka Amani, 2012, hlm.192.

Al Hafizh Bin Hajar Al 'Asqalani, Tarjamah Bulughul Maram

Lengkap Dengan Penjelasan-Penjelasan, Nganjuk: Penerbit Wicaksana Nganjuk, hlm.495.

Abu Walid Muhammad Ibn Ahmad Ibn Muhammad Ibn Rasyid, Bidayatul Al-Mujtahid Wanihayat Wamuqtasid, Bairut: Dar Al-Jiil, 1409 H/1989, Jilid II, hlm. 272.

Bakry, Nazar, Drs. H. "Problematika Pelaksanaan Fiqih Islam", Jakarta. 2015.

Choiruman Pasribu Suhrowardi K.Lubis, Hukum perjanjian dalam Islam, Jakarta: Sinar Grafika, cet 4, 2012, hlm. 139.

Departemen Agama RI "Al-Quran dan Terjemah". PT Toha putra Semarang. 2015.

DEPAG RI, Al-Qur'an dan Terjemah, Surabaya: Surya Cipta Aksara, 2013, hlm. 1995.

Fatoni, Abdurrahmat,Prof. Dr. H. M.Si. "Metodologi Penelitian Dan Teknik Penyusunan Skripsi'. PT. Asdi Mahasatya, Jakarta. 2012.

Fathi Ad-Duraini, Al-Fat Al-Islami Al-Muqaram Ma'al Al-Mazzahib, Demaskus: Mathba'ah Ath-Tharriyin, 1913, hlm. 555

Hasan, Gondes, M. "Berbagai Macam Transaksi dalam Islam (Fikih Muamalat) ’Jakarta. PT. Raja Grafido Persada. 2011.

H. Sulaiman Rasjid, Fiqih Islam, Bandung, Sinar Baru lgensindo, Cetakan Ke-38, 2011.

Ibnu Rusyd, terjemah: Drs. Imam Ghazali Said, MA. Dan Drs. Achmad zaidun. "Bidayatul Mujtahid "analisis Fiqih Para Mujtahid”, Jakarta. Pustaka Amani. 2014.

Imam Abu Zakariya Al-Anshori, Fathul Wahhab, Semarang; Thoha Putra, hlm193. 
Imam Taqayyudin Abu Bakir Al-Husaini, Kifayatul Ahyar Fi Halli Al Ihtisar, Nganjuk; Toha Putra, hlm.263

Joko P. Subagyo, Metode Penelitian dalam Teori dan Praktik, Jakarta: Rineka Cipta, 2014.

M. Ali Hasan, Berbagai Macam Transaksi dalam Islam (Fikih Muamalat), Jakarta: PT. Raja Grafido Persada, 2016.

M. Ali Hasan, Masail Fiqhiyah, Jakrta: PT. Raja Grafindo Persada, 2016, hlm.125

Muhamad Sholihul Hadi, Pegadaian Syari'ah, Jakarta: Salemba Diniyah, 2016, hlm.16.

R. Subekti dan R. Tjitrisdinyo, Kitab Undang-Undang Hukum Perdata, Jakarta: PT. Pradya Pramitra, 2013.

Sudarsono, Pokok-Pokok Hukum Islam, Jakarta: PT.Rinika Cipta, 2013.

Syafi'i Antonio, Muhammad "Bang Syriah: Dari Teori ke Praktik”. Jakarta. Gema Islami. 2013.

Suryabrata, Suryadi "metodologi Penelitian" akarta. Raja Grafindo Persada. 2015.

Sholikul Hadi Muhammad. "Pegadaian Syariah" Salemba Diniyah, Jakarta. 2016.

Suryadi Suryabrata, Metodologi Penelitian, Jakarta: Raja Grafindo Persada, 2015.

Terjemahan Nailul Autar:Himpinan Hadis-Hadis Hukum, terj. A. Qadir Hassan, Dkk, Surabaya, PT Bina Ilmu, hlm. 1785.

Prof. Dr. h. Abdurrahmat Fathoni, M.Si, Metodologi Penelitian Dan Teknik Penyusunan Skripsi, Jakarta: PT. Asdi Mahasatya, 2014. 